\title{
Improvement of the Solar-Thermal Characteristics of the Flat-Plate Collector Using a Composite Coating
}

\author{
Ruaa H. Jasim ${ }^{1}$, Ahmed A. Al-Tabbakh ${ }^{1, *}$ and Sinan M. Hasan ${ }^{2}$ \\ ${ }^{1}$ Department of Physics, College of Science, Al-Nahrain University, Baghdad, Iraq \\ ${ }^{2} \mathrm{Al}-\mathrm{Nahrain}$ Nanorenewable Energy Research Center, Al-Nahrain University, Baghdad, Iraq
}

\begin{tabular}{ll}
\hline \multicolumn{1}{c}{ Article's Information } & \multicolumn{1}{c}{ Abstract } \\
\hline Received: & A commercially available matt black paint is used as the primary component of \\
17.10 .2020 & a composite coating for low-temperature flat collector systems. The composite \\
Accepted: & coating is composed of the paint, carbon black powder (CBP) and lithium metal \\
13.01 .2021 & oxide (LMO) powder. The CBP and LMO powders are added on the top of the \\
Published: & primary paint to improve the solar-thermal conversion characteristics of the \\
13.03 .2021 & collector. The optical and solar-thermal conversion characteristics of these \\
Keywords: & coatings are investigated by means of optical microscopy, optical \\
Flat plat collector & spectrophotometry, total reflectance measurement, and the measurement of the \\
Selective coating & maximum collector temperature. Results show that the solar-thermal conversion \\
Heat transfer coefficient & response (maximum temperature) of the collector plate can be improved with the \\
Solar Irradiance & addition of the CBP and LMO powder at low concentrations. This is been \\
& demonstrated and discussed in this report. The coatings prepared in the present \\
& work can easily be applied on the collector surface and exhibit competing \\
& characteristics to other coatings.
\end{tabular}

DOI: 10.22401/ANJS.24.1.05

*Corresponding author: tabbakh2013@gmail.com

\section{Introduction}

Selective coatings are special types of coating layer(s) used in low and high temperature solar-thermal collectors [1-2]. These types of coatings are expected to absorb most of the incident solar radiation and convert it to thermal energy; this is the essential and most desirable property for energy conversion applications. These coatings are designed to have the maximum possible absorbance and minimum reflectance of the incident solar radiation while maintaining a minimum emittance value. Many materials were designed to closely meeting these specifications [36]. Among the promising materials investigated nickelpigmented aluminum oxide [7], nickel-aluminum (NiAl) alloy embedded into black paint [8], $\mathrm{CrNxOy} / \mathrm{SiO} 2$ on $\mathrm{Cu}(\mathrm{Si})$ substrate deposited by $\mathrm{DC}$ reactive magnetron sputtering method [9], black chrome or carbon-coating [10] have been investigated showing advantageous solarthermal conversion characteristics for flat plate collector systems. Recently, Lizama-Tzec et al. deposited black nickel coating on $\mathrm{Cu}$ substrate and compared its thermal and optical properties with the commercial FPC systems (i.e., $\mathrm{CuO}$ and nitrogen-doped $\mathrm{TiO} 2$ coatings) [11]. They reported reduced thermal losses of their selective coating after thermal treatment at $200{ }^{\circ} \mathrm{C}$ which was attributed to crystallinity characteristics of the coating. In 2020, Touaba et al. constructed a FPC which uses waste engine oil as a working and heat transfer fluid [12]. In the same year D. M. Herrera-Zamora et al. deposited nickel/black cobalt selective coating on a copper substrate for solar thermal collector application and investigated its thermal and optical properties [13]. They reported a solar radiation absorption of $95 \%$ and a thermal emission of $7 \%$ at $100{ }^{\circ} \mathrm{C}$. While many composite coatings may prove to be potential candidates for solar-thermal conversion applications other coating characteristics remain essential such as easiness of fabrication and application, durability and cost effectiveness.

In the present work a commercially available matt black paint (OMBP) is used as a primary coating of a flatplate collector. Additionally, carbon black powder (CBP) and lithium metal oxide (LMO) powder are air-sprayed on the top of the black paint to improve its solar-thermal conversion properties. As far as we know, these composite coatings of this work have not been extensively investigated for flat plate collectors. In addition, the CBP and the LMO particles may easily be obtained from expired rechargeable batteries which may otherwise present a source of contamination to environment. These coating are investigated by means of optical microscopy, optical spectrophotometry, total reflectance measurement, and the measurement of the maximum collector temperature. Besides being cost-effective costing solution, easily applicable on flat plate collectors the present coating composite is proved to have enhanced solar-thermal conversion characteristics. 


\section{Al-Nahrain Journal of Science}

ANJS, Vol.24 (1), March, 2021, pp. 24-29

\section{Materials and Methods}

The selective coatings performed in the present work are composed of a commercially available ordinary matt black paint (OMBP) with and without addition of carefully selected powders. The primary paint was applied on aluminum substrates of identical geometries (i.e., Al-plates of $1 \mathrm{~mm}$ thickness and $4 \times 4 \mathrm{~cm}^{2}$ area). A single layer of this paint was applied on the Al-plates after being cleaned with detergents, acetone and deionized water and dried with hot-blowers $\left(\sim 100{ }^{\circ} \mathrm{C}\right)$. Carbon black powder (CBP), lithiated transition-metal oxide (LMO) powder or both were added on the top of the paint by air-spraying (puffing) method. This method involves air-spraying of the powders on the top of the freshly applied paint from a distance of $30 \mathrm{~cm}$ to ensure the adhesion of the particles on the paint layer and their homogeneous distribution on its surface. The CBP was procured from EMFUTUR Technologies, Spain. The LMO powder was synthesized by combustion reaction, annealed at $800{ }^{\circ} \mathrm{C}$ for 48 hours and ball-milled at $300 \mathrm{rpm}$ for 6 hours to produce the fine powder of the material. The details of the synthesis and processing procedures are illustrated in reference [14]. The average size of the CBP is $\sim 500 \mathrm{~nm}$ while the LMO particles exhibit two size distributions with an average of $652 \mathrm{~nm}$ as shown in reference [14]. Three different coatings were prepared and investigated accordingly, these are the OMBP, the OMBP with CBP and the OMBP with CBP and LMO powder. Figure 1 shows the three specimens coated with these composite coatings.
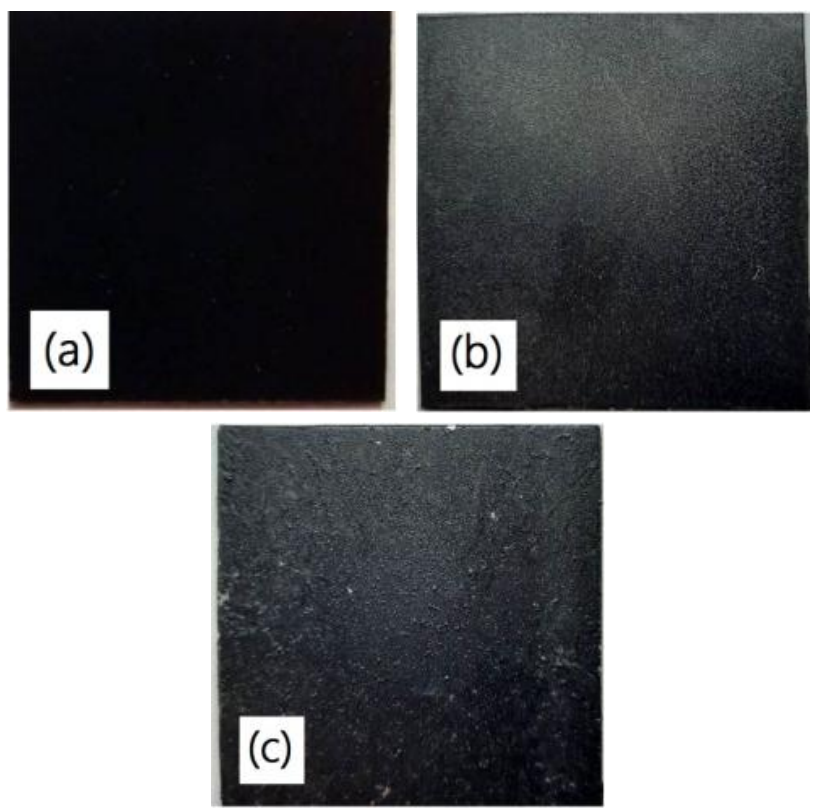

Figure 1. The Al-plates coated with different coatings. (a) Commercially available matt black MBP paint (b) MBP air-sprayed with carbon black powder (CBP) (c) MBP airsprayed with CBP and lithium metal oxide (LMO).

In order to measure the spectral reflectance of the coatings (i.e., the dependence of reflectance on the wavelength of the incident radiation) an optical spectrophotometer from Thorlabs was used. The wavelengths are ranging from $200 \mathrm{~nm}-1000 \mathrm{~nm}$ covering the UV, Visible, and NIR ranges of wavelengths. These are comparable to the components of the global solar radiation [15]. Sun light was used as the main source of the thermal radiation. The solar irradiance was measured using the TES1333R datalogging digital power meter. The power meter is oriented such that the sun light falls perpendicularly on the device sensor. This meter was also utilized for the measurement of the solar irradiance components, i.e., normal and diffused solar irradiances. The beam irradiance is the solar irradiance value, as measured by the digital solar power meter after excluding the diffused solar irradiance (DSI). This is achieved by placing a black-painted tube (internally painted) in front of the power meter as shown in Figure 2. In order to measure the total reflectance of the coatings, the tube setup mentioned earlier is used with slight modification. During the measurements, the tube was oriented such that the solar radiation makes 90 degrees with the plane normal to the axis of the cylindrical tube. The specimen makes 45 degrees with the tube axis while the digital power meter makes 90 degrees, such that equal values of incident and reflection angles were maintained during the measurements (see Figure 2).

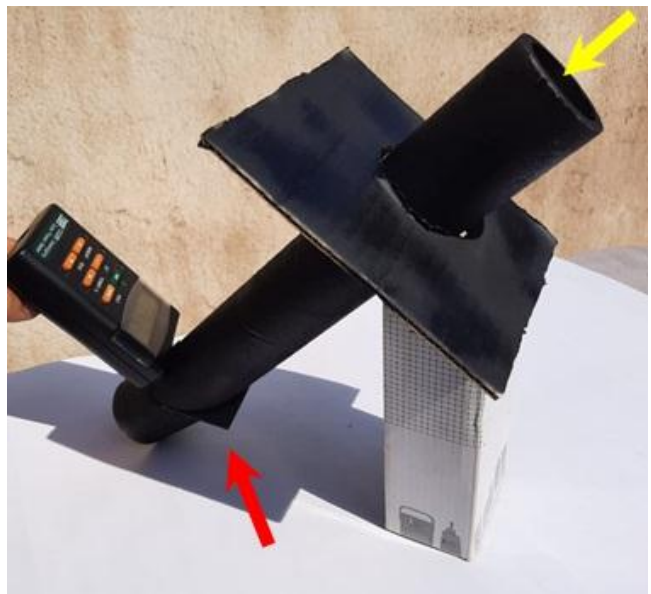

Figure 2. A home-made setup for the measurement of total reflection of the solar-radiation. The yellow arrow indicates the entrance of the solar-radiation. The red arrow indicates the specimen location.

The solar-thermal characteristics of the flat-plate collector were measured using a collector system free of working fluid as shown in Figure 3. The collector system is made up of cardboard box lined with a thermally insulating material (i.e., $4 \mathrm{~mm}$ sheets of compressed cork). The dimensions of the collector box are $250 \times 18 \times 4 \mathrm{~mm}^{3}$. The window is made up of a transparent glass having a thickness of $4 \mathrm{~mm}$. The thermocouple wires were admitted inside the collector box to measure the temperature of the substrate during the experiments. Another thermocouple was used to measure the glass temperature. 


\section{Al-Nahrain Journal of Science}

ANJS, Vol.24 (1), March, 2021, pp. 24-29

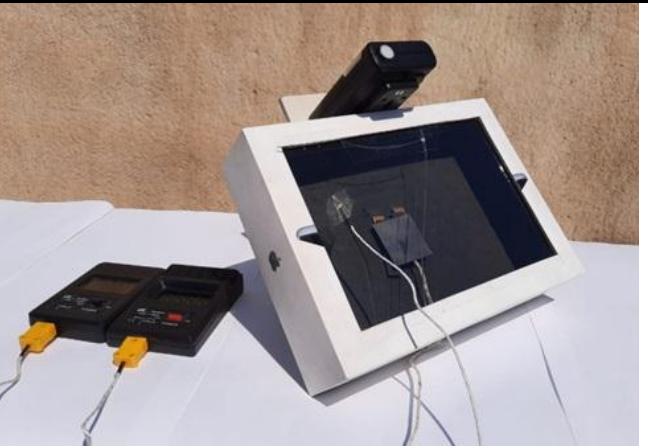

Figure 3. The flat-plate collector system used for the measurement of the solar-thermal characteristics.

\section{Results and Discussion}

Figure 4 (a)-(c) shows the coatings under an optical microscope with a nominal magnification of $200 \mathrm{X}$. These figures were taken before and after the addition of the CBP and the LMO powder. The homogeneous distribution of the powders may be realized by comparing the images in Figure 4 with those in Figure 1. The blackness of the coatings seems to be noticeably affected by the addition of the CBP and LMO powder on the top of the OMBP. These powders seem to reduce the blackness of the coating surface. However, the solar-thermal characteristics are decided not only be the effect of the visible region of the thermal radiation. This will be verified by the rest of the measurements performed in this work.
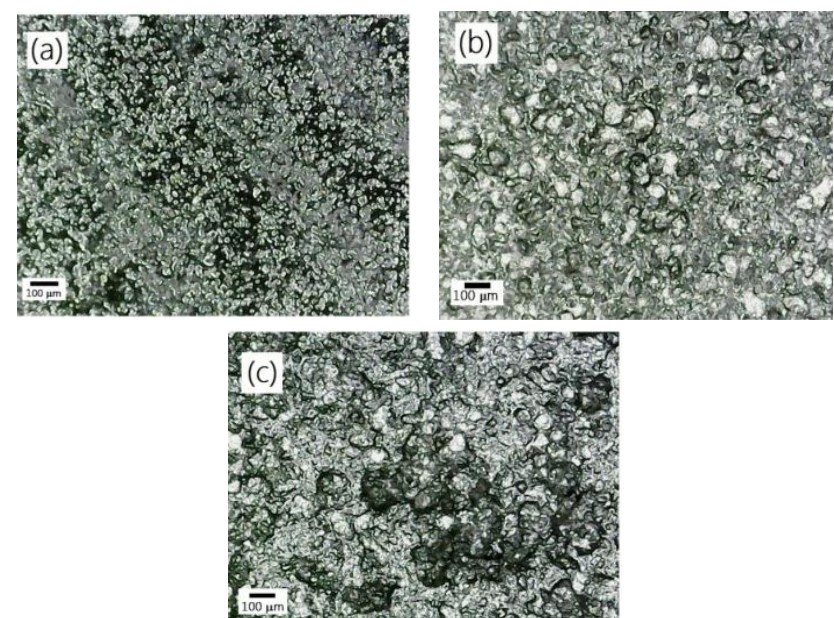

Figure 4. The composite coatings under optical microscope.

The behavior of the coating spectral reflectance (i.e., the dependence of reflectance on the incident wavelength) is shown in Figure 5. All the spectra exhibit similar features of the two-well distinctive peaks with varying intensities at wavelength values of $447 \mathrm{~nm}$ and 573-581 $\mathrm{nm}$ which belong to the visible region. Comparing the spectra of the OMBP, OMBP with $\mathrm{CBP}$ and OMBP with $\mathrm{CBP}$ and LMO powder (Figure 5 (a)-(c)) shows that the intensity of reflectance spectrum does not vary significantly with the addition of the powders on the top of the paint. The area under the curve which indicates the total reflectance over the entire range of the wavelengths shows similar behavior. Table 1 show that despite insignificant variation of the area under the curve a slight decrease of this value with the addition of CBP and LMO powder can easily be concluded. This is expected to enhance the solar-thermal characteristics of the coating, which will be verified by means of the total reflectance and solar-thermal response measurements.
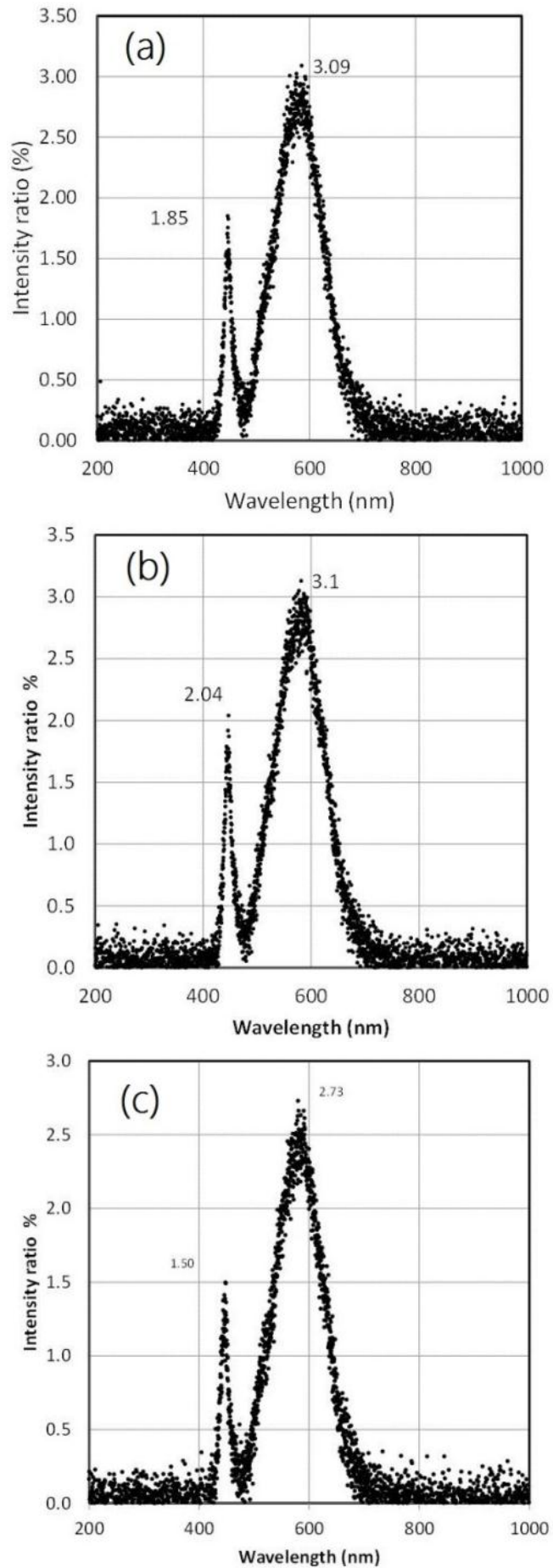

Figure 5. The spectral reflectance of the coatings (a) OMBP (b) OMBP with CB (c) OMBP with CBP and LMO. 


\section{Al-Nahrain Journal of Science}

ANJS, Vol.24 (1), March, 2021, pp. 24-29

Table 1. Spectra parameters of optical spectrophotometry measurements showing the total reflectance as estimated from the area under the curve.

\begin{tabular}{||c|c|c|c||}
\hline \multirow{2}{*}{ Coating type } & Peak \#1 & Peak \#2 & \multirow{2}{*}{ Area under the curve } \\
\cline { 2 - 4 } & Position (nm), Intensity ratio & Position (nm), Intensity ratio & \\
\hline \hline OMBP & $443,1.85$ & $597,3.09$ & 419 \\
\hline OMBP-CBP & $447,2.04$ & $582,3.12$ & 414 \\
\hline OMBP-CBP-LMO & $446,1.5$ & $577,2.73$ & 345 \\
\hline
\end{tabular}

The total reflectance measurements were accomplished using the home-made pyrheliometer as illustrated in section 2. Figure 6 shows the total reflectance measurement where the solar irradiance and beam irradiance are $1225 \mathrm{~W} / \mathrm{m}^{2}$ and $1132 \mathrm{~W} / \mathrm{m}^{2}$ respectively. The total reflected irradiance is measured for the three coatings in addition to the Al uncoated substrate and an ordinary, glass-coated mirror. The total reflectance values of the coatings show that the OMBP with CBP and LMO achieve the minimum total reflectance of $3.8 \%$ of the total incident radiation as compared with other coatings.

The addition of the CBP seems to have resulted into an increase of the total reflectance value. This contradiction could be attributed to the components of the solar radiation being reflected and measured in the total reflectance experiment. In order to verify the effect of adding the selected powders to the substrate coating the solar-thermal response measurement is performed. This response is measured using the collector system as the temperature rise of the flat plate collector with exposure to thermal radiation.

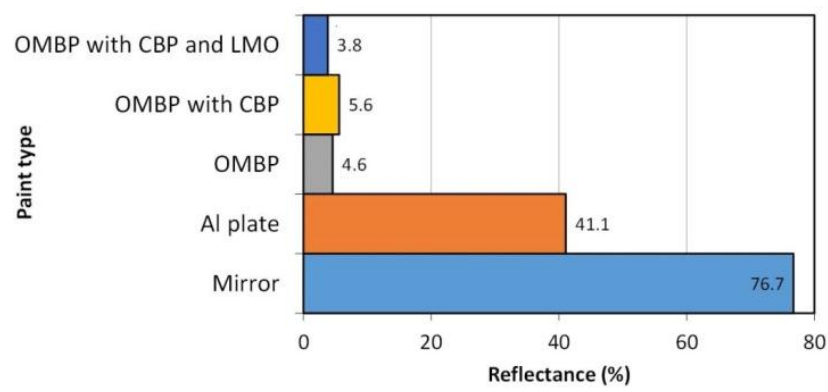

Figure 6. Total reflectance values of the selective coatings compared with reflectance from glass mirror and uncoated Al-plate.

The measurements (i.e., rise of the substrate temperature with time) were taken at time intervals of 30 min. All the specimens exhibited initially a fast increase of temperature with time followed by a slower increase until a constant temperature is reached. Such behavior is attributed to the conversion of the solar radiation being incident on the surface of the collector substrate into heat raising the substrate temperature. As the substrate, temperature rises the emissivity of the surface in the IR region increases too. An equilibrium, between the solar energy being collected and lost by the whole system (i.e., the collector), is attained when the temperature reaches its maximum value.

Figure 7 shows the solar-thermal response of the OMBP, OMBP-CBP and OMBP-CBP-LMO coatings in terms of the maximum temperature due to exposure to the solar radiation. Results show that the maximum temperature is $77.5{ }^{\circ} \mathrm{C}, 75.6{ }^{\circ} \mathrm{C}$ and $93.9{ }^{\circ} \mathrm{C}$ for the OMBP, OMBP-CBP and OMBP-CBP-LMO coatings respectively. This suggests that addition of CBP and LMO powder resulted into enhancement of the solar-thermal of the OMBP compared with the pure paint coating. Table 2 shows the solar-thermal conversion response of different paints/coatings investigated by other researchers. It is clear that the maximum achievable temperature depends greatly on the coating condition being single or multiple layers and the total irradiance. Other features, which were beyond the scope of the present work, represent important parameters to be taken in any paint comparison such as durability, corrosion characteristics and cost.

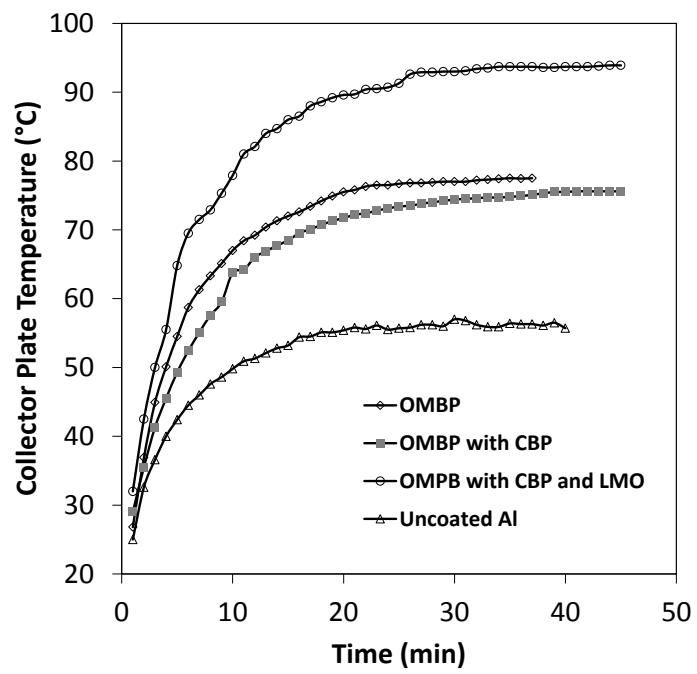

Figure 7. The solar-thermal response of the composite coatings as compared with that of the OMBP. 


\title{
Al-Nahrain Journal of Science
}

\author{
ANJS, Vol.24 (1), March, 2021, pp. 24-29
}

Table 2. The solar-thermal conversion response in terms of the maximum collector temperature for different coatings.

\begin{tabular}{|c|c|c|c|c||}
\hline & Coating / Paint & $\begin{array}{c}\text { Maximum Irradiance } \\
\left(\mathbf{W} / \mathbf{m}^{2}\right)\end{array}$ & $\begin{array}{c}\left(\mathbf{T}_{\text {max. }}\right) \\
\left({ }^{\circ} \mathbf{C}\right)\end{array}$ & Ref. \\
\hline \hline 1 & OMBP-CBP-LMO & 1150 & 93.9 & Present Work \\
\hline 2 & $\begin{array}{c}\text { 250 Selective Black Thurmalox Solar Collector Coating, } \\
\text { Graphene, CuO, }\end{array}$ & 919 & 43, & {$[16]$} \\
\hline 3 & CNT-CuO NPs dispersed in black paint & 964 & 82,57 & {$[17]$} \\
\hline 4 & NiAl Alloy embedded in black paint & 1000 & 69.7 & {$[18]$} \\
\hline 5 & CuO NPs mixed with black paint & 1100 & 97 & {$[19]$} \\
\hline 6 & Plasmonic Copper/Carbon foam/Cotton Fabric & 912 & 78.7 & {$[20]$} \\
\hline
\end{tabular}

As for the coating stability, it is worth mentioning that all the samples prepared were found to maintain their original coating conditions after 12 months of their application. In addition, the collectors are meant to be placed inside the collector case where the affecting environmental factors that may affect the coating condition are minimal. Furthermore, the black paint specifications are such that it withstands the relatively low temperatures of the collector operational conditions. This has also been confirmed from the coating condition after the solar-tothermal conversion measurements experiments.

\section{Conclusions}

Selective coatings for solar-thermal conversion in lowtemperature flat collector systems were successfully prepared from commercially available paint. Additional components of carbon black powder and lithium transition-metal oxide powder were successfully utilized to improve the solar-thermal conversion behavior of the solar collector. The optical and solar-thermal conversion characteristics of these coatings were successfully investigated by means of optical microscopy, optical spectrophotometry, total reflectance measurement, and measurement of the maximum collector temperature. While the ordinary matt black paint resulted in a maximum collector plate temperature of $77.5{ }^{\circ} \mathrm{C}$, a maximum collector plate temperature of $93.9{ }^{\circ} \mathrm{C}$ could be achieved after addition of carbon black powder and lithium metal oxide on the top of the paint. The coatings prepared in the present work could easily be applied on the surfaces of the flat plate collector systems.

\section{References}

[1] Panwar N. L., Kaushik S. C. and Kothari S., "Role of renewable energy sources in environmental protection: A review", Renew. Sustain. Ener. Rev. 15(3), 15131524, 2011. https://doi.org/10.1016/j.rser.2010.11.037.

[2] Samsul-Azha N. I., Hussin H., Nasif M. S. and Hussain T., "Thermal Performance Enhancement in Flat Plate Solar Collector Solar Water Heater: A Review". Processes 8(756), 1-14, 2020. http://doi.org/10.3390/ pr8070756.

[3] Feng C., Daniel K., Lu T., Li Y., Alexander P. L., Jiming B., Gang Ch. and Zhifeng R., "A high performance spectrally selective solar absorber based on ayttria-stabilized zirconia cermet with hightemperature stability", J. Ene. Environ. Sci. 8(10), 3040-3048, 2015. http://doi.org/10.1039/C5EE02066B.

[4] Ehab Al-Shamaileh, "Testing of a new solar coating for solar water heating applications", Sol. Ener. 84(9), 1637-1643, 2010. http://doi.org/10.1016/j.solener.2010. 06.003.

[5] Moncada M. L. T., Muñoza B. C., Yoshida M. M. and Rodríguez R. D., "Comparative experimental study of new absorbent surface coatings for flat plate solar collectors". Ener. Proce. 57, 2131-2138, 2014. http://doi.org/10.1016/j.egypro.2014.10.179.

[6] Yu H., Li J., Zhang Q., Pang W., Yan H. and Li G., "Thermal stability of chromium-iron oxidation mixture cermet-based solar selective absorbing coatings", Molecules 25(5), 1178, 1-11, 2020. http://doi.org/10. /molecules25051178.

[7] Wazwaz A., Salmi J., Hallak H. and Bes R., "Solar thermal performance of a nickel-pigmented aluminum oxide selective absorber", Renew. Ener. 27(2), 277292, 2002. http://doi.org/10.1016/s0960-1481(01) 00192-6.

[8] Ehab Al-Shamaileh, "Testing of a new solar coating for solar water heating applications", Sol. Ener. 84(9), 1637-1643, 2010. http://doi.org/10.1016/j.solener.2010. 06.003.

[9] Liang W., Junhua G., Zhimin L., Lingyan L., Fei X. and Hongtao C., "Thermal aging characteristics of $\mathrm{CrNxOy}$ solar selective absorber coating for flat plate solar thermal collector applications", Sol. Ener. Mater. Sol. Cell. 114, 186-191, 2013. http://do.org/10.1016/j. solmat.2013.03.005.

[10] Sakhaei S. A. and Valipour M. S., "Investigation on the effect of different coated absorber plates on the thermal efficiency of the flat-plate solar collector", J. Therm. Anal. Calori. 140, 1597-1610, 2020. https://doi.org/10.1007/s10973-019-09148-X.

[11] Lizama-Tzeca F. I., Herrera-Zamoraa D. M., ArésMuzioa O., Gómez-Espinozab V. H., SantosGonzálezc I., Cetina-Dorantesa M., Vega-Poota A. G., García-Valladaresb O. and Oskama G., "Electrodeposition of selective coatings based on black nickel for flat-plate solarwaterheaters", Sol. 


\section{Al-Nahrain Journal of Science \\ ANJS, Vol.24 (1), March, 2021, pp. 24-29}

Ene. 194, 302-310, 2019. http://doi.org/10.1016/j. solener.2019.10.066.

[12] Touaba O., Cheikh M. S. A., Slimani M. E., Bouraiou A., Ziane A., Necaibia A. and Harmim A., "Experimental investigation of solar water heater equipped with a solar collector using waste oil as absorber and working fluid.", Sol. Ene. 199, 630-644, 2020. https://doi.org/10.1016/j.solener.2020.02.064.

[13] Herrera-Zamora D. M., Lizama-Tzeca F. I., SantosGonzález I., Rodríguez-Carvajal R. A., GarcíaValladares O., Arés-Muzio O. and Oskam G., "Electrodeposited black cobalt selective coatings for application in solar thermal collectors: Fabrication, characterization, and stability", Sol. Ener. 207, 11321145, 2020. http://doi.org/10.1016/j.solener.2020.07. 042.

[14] Ahmed A. Al-Tabbakh and Norlida Kamarulzaman, "Evaluation of the electrochemical capacity of spinel $\mathrm{Li}_{1.0348} \mathrm{Mn}_{1.9152} \mathrm{Fe}_{0.0494} \mathrm{O}_{4}$ compound from combined $\mathrm{X}$-ray diffraction and particle size distribution measurements, Journal of Solid State Electrochemistry 18, 2411-2418, 2014, http://doi. org/10.1007/s10008-014-2486-z.

[15] Solar, UV., Ozone Layer and Spectral Irradiance Data, "ORIEL PRODUCT TRAINING".

[16] Alami A. H. and Aokal K., "Enhancement of spectral absorption of solar thermal collectors by bulk graphene addition via high-pressure graphite blasting", Ener. Conv. Manag. 156, 757-764, 2018. https://doi:10.1016/j.enconman.2017.11.040.

[17] Abdelkader T. K., Zhang Y., Gaballah E. S., Wang S., Wan Q. and Fan Q., "Energy and exergy analysis of a flat-plate solar air heater coated with carbon nanotubes and cupric oxide nanoparticles embedded in black paint", J. Clean. Prod. 119501, 2019. https://doi:10.1016/j.jclepro.2019.119501.

[18] Al-Shamaileh E.,'Testing of a new solar coating for solar water heating applications", Sol. Ener. 84(9), 1637-1643, 2010. https://doi:10.1016/j.solener.2010. 06.003.

[19] Sivakumar S., Velmurugan C., Jacob Dhas D. S. E., Solomon A. B. and Dev Wins K. L., "Effect of nanocupric oxide coating on the forced convection performance of a mixed-mode flat plate solar dryer", Renew. Ener. 155, 1165-1172, 2020. https://doi.org/ 10.1016/j.renene.2020.04.027.

[20] Sebastian G. and Thomas S., "Influence of providing a three-layer spectrally selective floating absorber on passive single slope solar still productivity under tropical conditions", Energy 214, 118848, 2020. https://doi.org/10.1016/j.energy.2020.118848. 